\title{
HISTOPATHOLOGICAL CHANGES IN RESPONSE TO Ceratocystis manginecans IN MANGO (Mangifera indica)
}

\author{
Romana Anjum ${ }^{1}$, Shahbaz Talib Sahi ${ }^{2}$, Iqrar Ahmad Khan ${ }^{3}$ and Imran-ul-Haq ${ }^{2}$ \\ ${ }^{1}$ University of Agriculture, Faisalabad Sub-Campus Vehari/Burewala-61100, Pakistan; ${ }^{2}$ Department of Plant \\ Pathology, University of Agriculture, Faisalabad-38040, Pakistan; ${ }^{3}$ Institue of Horticultural Sciences, University of \\ Agriculture, Faisalabad-38040, Pakistan. \\ *Corresponding author's e-mail: romana.anjum@uaf.edu.pk
}

Ceratocystis manginecans is a destructive systemic fungus and a major cause of mango sudden decline. Heavy losses to the mango industry in Pakistan are due to this disease. This study was designed to evaluate the histological changes in mango seedlings inoculated with $C$. manginecans. The pathogenic fungus was inoculated to indigenous mango germplasm of Punjab, Azad Jammu and Kashmir. After one week of inoculation, plants started showing disease symptoms including gum exudation, wilting of leaves, discoloration of stem, and bark splitting. Discolored bark from diseased plants was peeled off and internal symptoms were studied and confirmed for $C$. manginecans infection. Diseased stems were transversely sliced and fixed in formaline acetic alcohol (FAA), double stained and examined under compound microscope. The epidermal tissues were found to be collapsed due to sclertization of xylem vessels, fungal hyphal growth, production of phenolics and tyloses. Deposition of phenolics and formation of tyloses in turns leads to the obstruction of water and minerals uptake, therefore, plants start wilting and then decline.

Keywords: Mango sudden decline, pathogenicity, histopathology, tyloses, systemic fungus

\section{INTRODUCTION}

Mango (Mangifera indica L. Family: Anacardiaceae) is one of the most important indigenous fruit of Pakistan and is entitled the "King of fruits" due to its excellent flavor, taste and aroma. Mangoes are believed to be rich in vitamins (A, C, E), sugars, minerals and dietary fiber (Ajila and Parsada, 2008). World mango production is 38.7 million tons, from which $98 \%$ is produced by developing countries (FAO, 2013) where Pakistan is ranked $5^{\text {th }}$ with 1.9 million tons from an area of 17.3 thousands hectares; however, it has decreased to 1.6 million tons from the same area due to diseases and insect pests.

Mango sudden decline (MSD) is presently the major limiting factor in successful mango production. In 2005, the disease was first reported from Pakistan (Malik et al., 2005) and caused up to 60\% losses (Al-Subhi et al., 2006; Saeed et al., 2007). Mango groves in Southern Punjab and Sindh have been suffering from this sudden decline (Masood et al., 2008). The symptoms of Ceratocystis manginecans caused by MSD are characterized by defoliation, vascular discoloration, marginal necrosis, leaf chlorosis, root degradation (Ploetz et al., 1996), tip die-back, stem bleeding (Pernezny and Ploetz, 2000), gum exudation with severe rotting smell, bark splitting, total or partial wilting of the tree by successive browning of leaves and ultimately tree death. Mango bark beetle (Hypochryphalous mangiferae) is considered as a vector of this disease (Al-Adawi, 2002; Al-
Adawi et al., 2003; Ribeiro, 1980; Yamashiro and Myazaki, 1985; Ploetz, 2003).

C. manginecans is considered to be a cryptic species of the C. fimbriata s.l. spp. complex, which causes wilting and sudden decline of the whole tree. C. manginecans stimulates the tree to produce phenolics and formation of tyloses in vascular tissues of mango plants on local Omani germplasm (Al-Sadi et al., 2010). Botryodiplodia theobromae was tested by artificial inoculation to confirm the pathogenicity of quick decline (Mahmood and Gill, 2002). Similarly, $C$. fimbriata and Lasiodiplodia theobromae were recovered from artificially inoculated infected mango trees (Al-Adawi et al., 2006) during pathogenicity testing. The histology of declined mango trees was studied in response to Fusarium spp. and other saprophytic fungi, showing that the fungal hyphae gradually invade the xylem tissues, causing death of the infected area of tree branches and stem (Rajput and Rao, 2007). The histological changes on many commercial varieties in response to $C$. manginecans have not been investigated. This study was designed to investigate the histopathological changes in response to $C$. manginecans, especially in Pakistani mango germplasm.

\section{MATERIALS AND METHODS}

C. manginecans isolates: Four randomly chosen isolates CMK04, CMM12, CMG23 and CMR35 from four mango growing districts of southern Punjab (Khanewal, Multan, 
Muzaffargarh and Rahim Yar Khan, respectively) were used in this study. Samples were collected from each respective area and then $C$. mangenicans was recovered from the samples on Malt Extract Agar (MEA) media.

Pathogenicity testing: A pathogenicity trial was designed to evaluate the pathogenicity of four fungal isolates on one year old healthy growing mango seedlings from each respective mango growing districts of southern, northern Punjab and AJK in a disease-free environment, in a screen house of Institute of Horticultural Sciences. The I-cut window method as described by Mullen et al. (1991) and Al-Adawi et al. (2006) was used to inoculate the mango germplasm. Each mango seedling stem was wounded by making an I-cut window of $7.5 \mathrm{~mm}$ long and $5 \mathrm{~mm}$ wide with a sterilized scalpel above the graft union and soil level (approximately $20 \mathrm{~cm})$. Mycelial plugs $(5 \mathrm{~mm}$ diameter) of each fungal isolate on MEA medium was inserted into the I-cut windows of mango seedling stems. Inoculated windows were covered with moistened sterilized cotton swabs and banded with paraffin wax strips. Control seedlings were treated with uninoculated MEA plugs. The inoculated seedlings were watered twice per week, which is the water requirement of healthy seedlings.

Data on disease progression was recorded on a weekly basis by documenting the disease-discolored area of lesion length and scored disease symptoms separately in response to the upward and downward movement of the fungus. After complete collapse of inoculated seedlings, bark tissues were removed with strips of white and black vascular tissues and processed for re-isolation of isolates to confirm the presence of the test pathogen (C. manginecans) of MSD. Statistical analysis of data was carried out for pathogenicity testing of germplasm using SAS statistical software (SAS Institute, NC, USA, 1990). Correlation analysis was used to assess the relationship between progress of disease symptoms, wilting, discoloration, and movement of fungal mycelium in the stem with respect to time.

Histopathological studies: Histopathological studies of vascular tissues of diseased nursery plants were carried out by the prescribed method of Al-Sadi et al. (2010). Two 10 $\mathrm{mm}$ transverse sections of diseased stem were taken $3 \mathrm{~cm}$ above the inoculation point and these sections were fixed in FAA (v/v formalin $10 \%$, acetic acid 5\%, ethyl alcohol 50\% and distilled water $35 \%$ ) for 48 hours and subsequently transferred to acetic alcohol solution ( $\mathrm{v} / \mathrm{v}$ acetic acid $25 \%$ and ethanol $75 \%$ ) for long term storage. After that, fixed sections were further cut into $3 \mathrm{~mm}$ transverse sections by freehand thin transverse sectioning technique. Slides were prepared by serial dehydrations in ethanol using standard double-stain technique of safranine and fast green stains and examined microscopically. Transverse sections from healthy or un-inoculated mango seedlings were examined as controls.

\section{RESULTS AND DISCUSSION}

Pathogenicity testing: Necrosis, gummosis and wilting with discoloration are common in Ceratocystis induced wilt diseases (Van Wyk et al., 2007). Our pathogenicity trial on inoculation of mango seedlings resulted in the production of

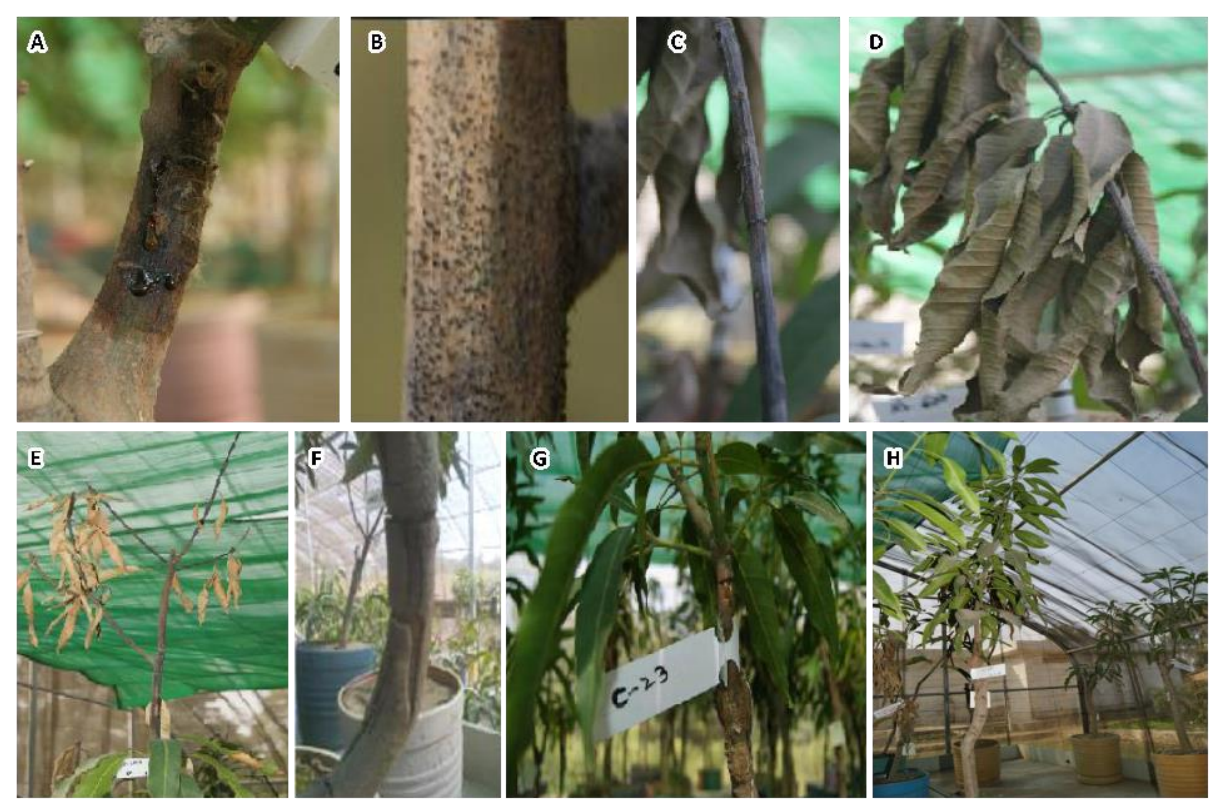

Figure 1. Symptoms development in $C$. manginecans inoculated mango germplasm. A) Gum exudation; B) Perithecial growth with ascospore masses on severely infected seedlings; C) discoloration of branches/stem; D,E) Wilting stages; F) Bark splitting; G,H) controlled seedlings. 
gum exudation, followed by discoloration of stems, wilting of leaves and bark splitting which were typically same as recorded during surveys of mango orchards (Fig. 1), but the first symptoms were observed after one week of inoculation (Fig. 2).

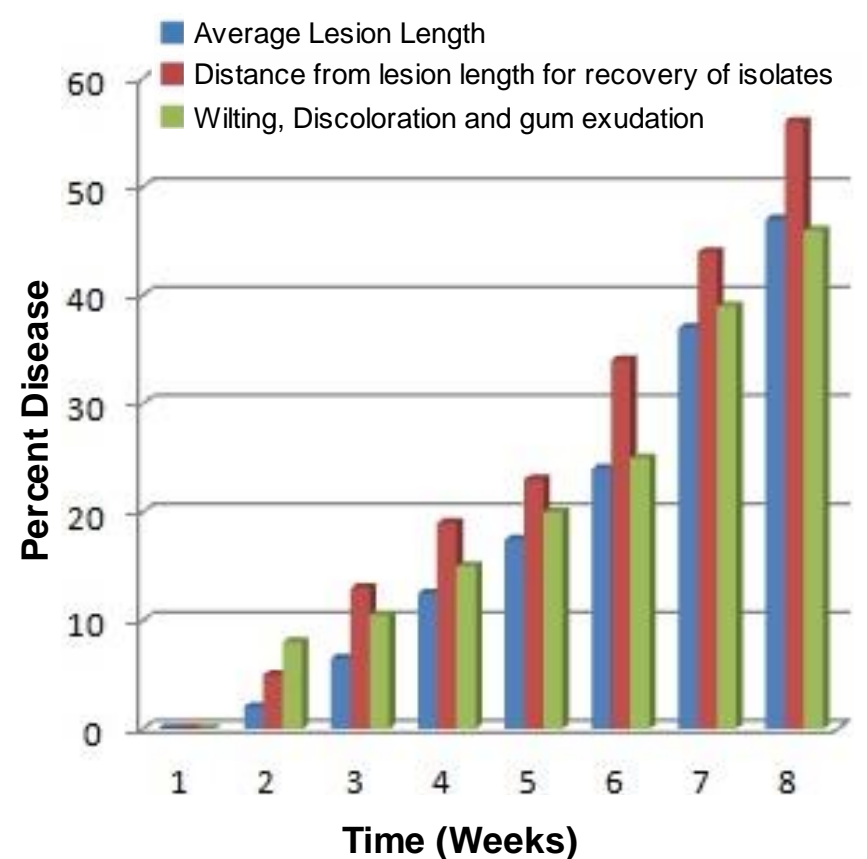

Figure 2. Percent disease with mean average length of lesions, distances for recovery of inoculated isolates and symptoms development. Bar graphs showed disease starts after one week of inoculation as on first week there is no lesion and disease symptoms developed.

Inoculated mango seedlings produced stem discoloration with no significant difference between upward $(47.00 \mathrm{~cm}$ of week eight) and downward movement $(46.96 \mathrm{~cm}$ of week eight) of the $C$. manginecans isolates (Fig. 3). Xylem vertically provided the nutrients to the plant parts which support the $C$. manginecans growth to not get any significance obstruction from causing severe wilt symptoms (Al-Sadi et al., 2010). Upward and downward movement of fungal hyphae in relation to disease development was also positively correlated and approximately similar to each other. Upward movement showed a positive correlation $\mathrm{R}^{2}=$ 0.931 and increased the disease 0.847 times with one unit change, while downward movement showed an 0.843 times increase in disease with strong correlation $\mathrm{R}^{2}=0.931$ (Fig. 3 ). The values of correlation analysis indicate a significant and positive correlation between rate of opposite directions of fungal progression, tissue discoloration and progress of disease ( $\mathrm{r} \geq 0.99 ; \mathrm{P}<0.05)$ (Fig. 3). One unit change in disease favorable conditions with respect to time increased $5.5443 \mathrm{e}^{0.0447 \mathrm{x}}$ percent disease in exponential correlation while in linear correlation one unit change increased percent disease by 0.8556 times (Fig. 4). Rate of internal discoloration of wood tissues showed no significance difference in opposing directions but severity decreased with increasing distance from point of inoculation. Similarity in upward and downward movements of $C$. manginecans growth, discoloration of mango seedlings and disease progress was also reported by Al-Sadi et al., (2010).

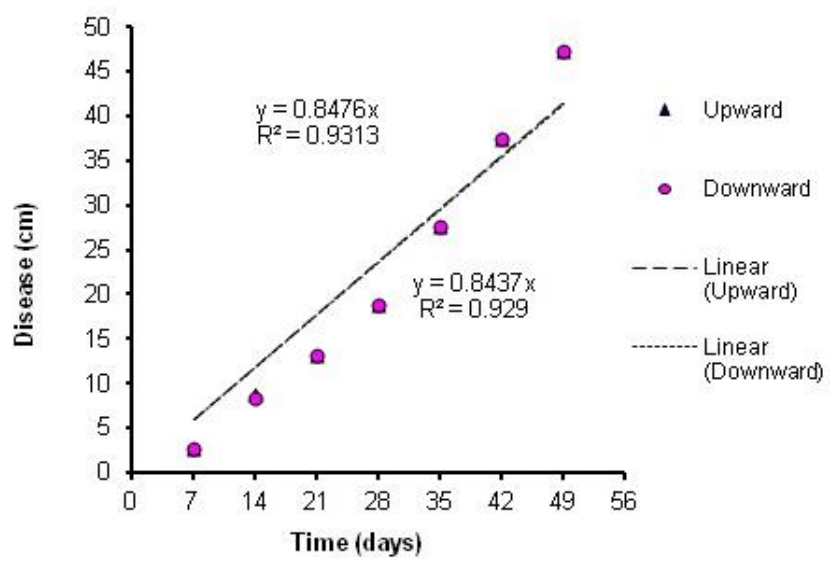

Figure 3. Positive linear correlation of percent disease (cm) in terms of upward and downward movement of fungal hyphae in relation to time with approximately, similar strong $R^{2}$ values.

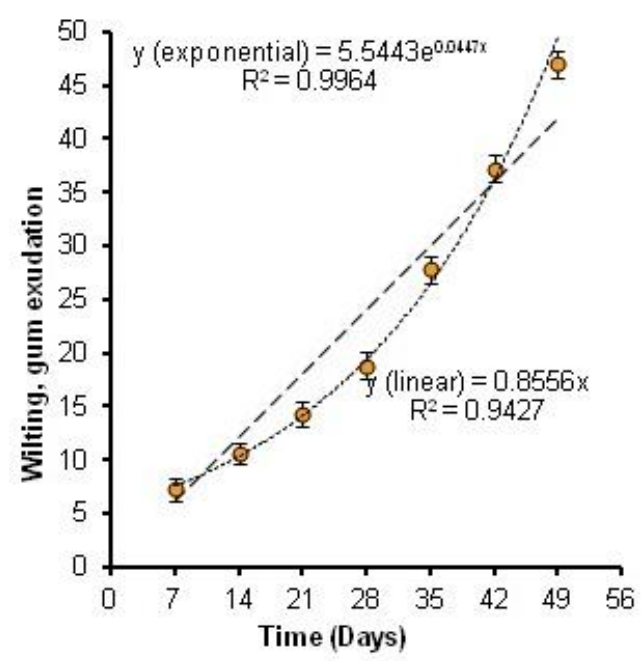

Figure 4. Positive exponential and linear correlation with strong $R^{2}$ values of wilting, discoloration and gum exudation in relation to time.

C. manginecans was also recovered from areas in the stem ahead of discoloration which indicates the colonization rate of the fungus is higher inside the vascular tissues of mango seedlings. Re-isolation resulted in the same fungal isolates of $C$. manginecans as inoculated on the seedlings, showing the 

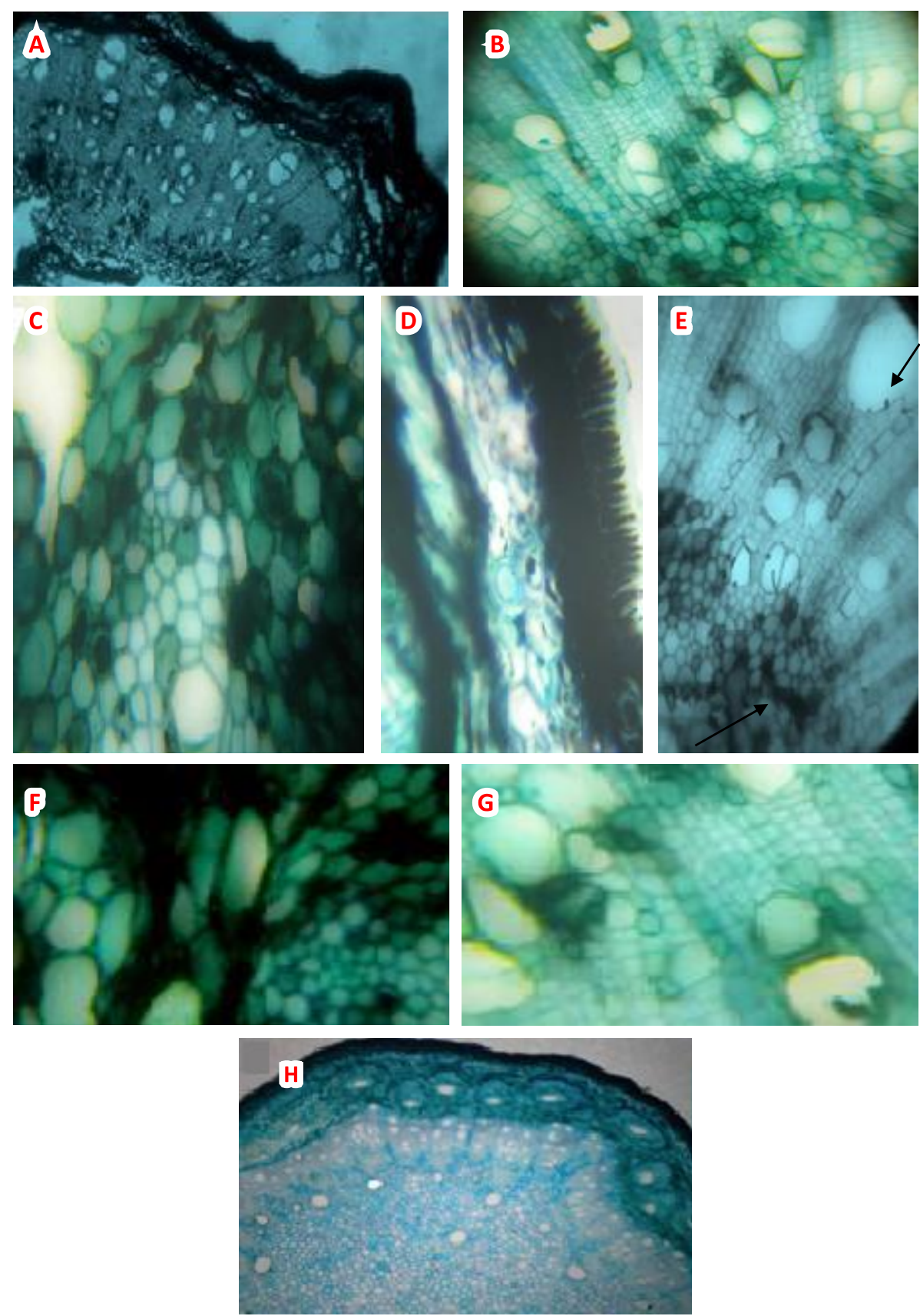

Figure 5. Histological studies of $\boldsymbol{C}$. manginecans inoculated seedlings vs healthy seedlings: A) Inoculated Mango seedling; B,C) Production of Phenolic compounds with discoloration of cells in xylem axial arrays and pith; D) collapsed stem dermal tissues; E) Arrow heads are showing fungal hyphae; F,G) Production of tyloses; H) Healthy Mango seedling Tissue.

pathogenicity of isolates used for inoculation, while control seedlings were unable to give any type of fungal isolates. Similarly in other studies, after disease development, the inoculated C. manginecans fungus was recovered from mango plants (Al-Adawi et al., 2013).
Histpathological studies: C. manginecans, upon inoculation in mango seedlings (Fig. 5A), shows discoloration of stem cells due to the deposition of phenolic compounds in higher quantity (Fig. 5B,C). Wood decay and discoloration or total collapse of dermal tissues due to $C$. manginecans is a common feature of seedling decay, followed by wilting (Fig. 
5D). Deposition of phenolic compounds, production of gums and cells necrosis results in xylem and phloem dysfunction in the translocation of water and mineral uptake. Isolates grow fast even against gravity, and ultimately, seedlings start suffering in disease progression with a dry, rigid surface, loss of water and nutrients (Fig. 5E). Original cell size shrunk with dark coloration. The advancement of $C$. manginecans hyphae in xylem vessels produced tyloses which prevents the normal uptake of water (Fig.5F,G). Axial rays, xylem vessels and pith cells show sclereids due to the loss of water. Stem epidermis showed increasing thickness and cell area collapsed with sclerenchyma thickness, whereas, healthy tissues did not show any thickness of cell epidermis and sclereids. Histological studies of control mango seedlings showed a healthy tissue appearance (Fig. $5 \mathrm{H})$ without any deposition of phenolic compounds or formation of tyloses as compared to the inoculated mango seedlings. In the agreement to the above results, darkened tissues, production of phenolics, gum, tyloses and fungal mycelium were reported in inoculated mango seedlings which were responsible for wilt and death of infected mango trees (Al-Sadi et al., 2010).

This suggests that disease progression in Pakistani mangos in response to Pakistani isolates is similar to that has been observed using isolates and germplasm from Oman.

\section{REFERENCES}

Al-Sadi, A.M., F.A. Al-Ouweisi, N.K. Al-Shariani, A.O. AlAdawi, E.J. Kaplan and M.L. Deadman. 2010. Histological changes in mango seedlings following infection with ceratocystis manginecans, the cause of mango decline. J. Phytopathol. 158:738-743.

Ajila, C.M. and R.U.J.S. Parsada. 2008. Protection against hydrogen peroxide induced oxidative damage in rat erythrocytes by Mangifera indica L. peel extract. Food Chem. Toxicol. 46:23-28.

Al-Subhi, A.M., A.O. Al-Adawi, M.V. Wyk, M.L. Deadman and M.J. Wingfield. 2006. Ceratocystis omanensis, a new species from diseased mango trees in Oman. Mycol. Res. 110: 237-245.

Al-Adawi, A.O. 2002. The biology of Diplodia theobromae associated with mango sudden decline disease in Oman. M.Sc. Diss., Dept. Crop Sci., Sultan Qaboos University, Sultanate of Oman.

Al-Adawi, A.O., M.L. Deadman, A.K. Al-Rawahi, A.J. Khan and Y.M. Al-Maqbali. 2003. Diplodia theobromae associated with sudden decline of mango in the Sultanate of Oman. Pl. Pathol. 52:419-424.

Al-Adawi, A.O., M.L. Deadman, A.K. Al-Rawahi, Y.M. AlMaqbali, A.A. Al-Jawahri, B.A. Al-Saadi, I.S. Al-Amri and M.J. Wingfield. 2006. Aetiology and causal agents of mango sudden decline disease in the Sultanate of Oman. Eur. J. Pl. Pathol. 116:247-254.
Al-Adawi, A.O., B.A. Al-Sadi, M. H. AL-Jabri and M.L. Deadman, 2013. Evaluation of mango cultivars for resistance to infection by Ceratocystis manginecans.Proc. IXth Intl. Mango Symposium. Ed. Ping Lu, Acta Hort. 992.

FAO. 2013. Statistical report on mango production in Pakistan. FAO Statistical Division, Pakistan.

Malik, M.T., S.M. Khan, A.A. Dasti and M.R. Kazmi. 2005. First record of Ceratocystis fimbriata, causal organism of mango sudden death in Pakistan. Pak. J. Phytopath. 17: $187-191$.

Mahmood, A. and M.A. Gill, 2002. Quick decline of mango and in vitro response of fungicides against the disease. Int. J. Agri. \& Biol., 4:39-40.

Masood, A., S. Saeed and A. Sajjad. 2008. Characterization and damage patterns of different bark beetle species associated with mango sudden death syndrome in Punjab, Pakistan. Pak. Entomol. 30:163-168.

Mullen, J.M., C.H. Gilliam, A.K. Hagan and G. MorganJones. 1991. Canker of dogwood caused by Lasiodiplodia theobromae, a disease influenced by drought stress or cultivar selection. Pl. Dis. 75:886-889.

Pernezny, K. and R. Ploetz. 2000. Some common diseases of mango in Florida. Florida Cooperative Extension Service, Inst. Food \& Agri. Sci., University of Florida. pp.1-23.

Ploetz, R.C. 2003. Diseases of mango. In: R.C. Ploetz (ed.), Diseases of Tropical Fruit Crops. CAB Int., Wallingford, UK. pp.327-363.

Ploetz, R.Z., D. Benscher, A. Vazquaq, A. Colls, J. Nagel and B. Schaffer. 1996. A re-examination of mango decline in Florida. Pl. Dis. 80:644-648.

Rajput, K.S. and K.S. Rao. 2007. Death and decay in the trees of mango (Mangifera indica L.). Microbiol. Res. 162:229-237.

Ribeiro, I.J.A. 1980. Seca da manguera, agents causais e studio da molesta. In: Anais do I symposio brasiliero sobre a cultura de mangeura. Sociedad brasileira de Fruticultura, Jacoticobal. pp.123-130.

Saeed, S., N. Hussain and R. Attique. 2007. Etiology and management of sudden phenomenon in mango; $2^{\text {nd }}$ Annual Report. Dept. Entomol. Uni. Coll. Agri. B.Z.U. Multan, Pakistan. pp.12-40.

SAS Institute Inc. 1990. SAS/STAT User's guide, version 6, Cary, NC:SAS Inst. Inc.

Van Wyk, M., A.O. Al Adawi, I.A. Khan, M.L. Deadman, A.A. Al Jahwari, B.D. Wingfield, R. Ploetz, and M. J. Wingfield, 2007. Ceratocystis manginecans sp. nov., causal agent of a destructive mango wilt disease in Oman and Pakistan. Fungal Diversity 27: 213-230.

Yamashiro, T. and I. Myazaki. 1985. Principal pests and diseases of mango (Mangifera indica L.) in the state of Sao Paulo and updated control methods. Biologico. 51:41-50. 